\title{
THE CORONAVIRIDAE NOW COMPRISES TWO GENERA, CORONAVIRUS AND TOROVIRUS: REPORT OF THE CORONAVIRIDAE STUDY GROUP
}

\author{
D. Cavanagh ${ }^{1}$, D.A. Brian, M.A. Brinton, L. Enjuanes, K.V. Holmes, \\ M.C. Horzinek, M.M.C. Lai, H. Laude, P.G.W. Plagemann, S.G. Siddell, \\ W.J.M. Spaan, F. Taguchi and P.J. Talbot \\ ${ }^{1}$ Division of Molecular Biology \\ AFRC Institute for Animal Health \\ Compton Laboratory \\ Compton, Newbury RG16 0NN, UK
}

\begin{abstract}
At the April 1992, mid-term meeting of the International Committee on Taxonomy of Viruses (ICTV) a proposal from the Coronaviridae Study Group (CSG) to include the torovirus genus in the Coronaviridae was accepted. Following another proposal, the arterivirus genus was removed from the Togaviridae but not assigned to another family. The arteriviruses have some features in common with the Coronaviridae but also have major differences. After much debate, culminating in September 1992, it was decided that the CSG would not recommend inclusion of arterivirus in the Coronaviridae. It was agreed that (a) the nomenclature used for coronavirus genes, mRNAs and polypeptides (Cavanagh et al., 1990) should be used for toroviruses, (b) that the small (about 100 amino acids) membrane-associated protein, which is distinct from the integral membrane glycoprotein M, associated with virions of infectious bronchitis (Liu \& Inglis, 1991) and transmissible gastroenteritis (Godet et al., 1992) coronaviruses would be referred to by the acronym sM (lower case 's') and (c) that 'pol' (polymerase) should be used as a working term for gene 1 , which comprises open reading frames (ORFs) $1 \mathrm{a}$ and $1 \mathrm{~b}$ in both genera of the Coronaviridae.
\end{abstract}

\section{COMPARISON OF CORONAVIRUSES AND TOROVIRUSES}

The main features of the toroviruses, of which there are two known species (Berne virus and Breda virus), and coronaviruses are described in detail in the chapter by Snijder 
et al. in this volume. The decision to include the toroviruses in the Coronaviridae was in recognition of the many characteristics shared by these two genera, most of the similarities having come to light only recently with the sequencing of a large part of the genome of Berne virus, the type species and most thoroughly studied torovirus. Some of the features of the two genera are summarized in Table 1. Both genera comprise viruses which are enveloped and have prominent spike (S) glycoproteins of $\sim 200 \mathrm{kDa}$ which exhibit a coiled-coil structure in the carboxy-terminal, membrane-anchoring half. Each virus possesses an integral membrane protein $(\mathrm{M})(\sim 25 \mathrm{kDa})$ with three membrane-spanning sequences in the amino-terminal half. The genomes are single-stranded, non-segmented, positive-sense RNAs of $\sim 30 \mathrm{~kb}$, the first two-thirds being the gene (number 1) which encodes the presumptive RNA-dependent RNA polymerase. Gene 1 codes for two overlapping ORFs, 1a and $1 \mathrm{~b}$, ribosomal frameshifting being involved in the translation of the second ORF. Five or more subgenomic mRNAs are generated forming a 3'coterminal nested set. Only the 5' sequence not possessed by the next smaller mRNA is translated. Overall genome organisation is similar, the gene order being 5'-pol-S-M-N-3', where $\mathrm{N}$ is the nucleocapsid protein. There are additional genes, some of which are not common between the two genera and, indeed, not possessed by all members of one genus e.g. the haemagglutinin-esterase glycoprotein of some coronaviruses.

A number of features require that the coronaviruses and toroviruses should be in separate genera. There is virtually no sequence similarity between the two groups. The $\mathrm{N}$ proteins differ greatly in size (Table 1) and form differently shaped nucleocapsids. The viruses are of similar size, about $130 \mathrm{~nm}$ in diameter, the coronaviruses being pleomorphic but roughly spherical in shape. In negatively-stained preparations toroviruses can look very similar to coronaviruses but in ultra-thin sections toroviruses can have disc-, kidney- or rod shapes. Leaders are present on the 5'termini of coronavirus mRNAs but these have not been found on Berne virus mRNAs.

\section{ARTERIVIRUSES}

The genus arterivirus includes equine arteritis and lactate dehydrogenase-elevating virus. Like members of the Coronaviridae, the arteriviruses are enveloped, with a singlestranded, non-segmented, positive-sense RNA genome and with similar genome organisation (Table 1). A 3' co-terminal nested set of five or more mRNAs are produced, ribosomal frameshifting is involved in translation of the pol gene and the integral membrane protein has a triple membrane-spanning domain. However, there are several major differences from the other two genera. The arterivirus nucleocapsid is icosahedral, the virions being only $50-70 \mathrm{~nm}$ in diameter. The surface glycoprotein is neither prominent nor does it have a coiled-coil structure and comprises a much smaller polypeptide, as do $\mathrm{M}$ and $\mathrm{N}$, than the corona- and torovirus counterparts. The genome is only $\sim 13 \mathrm{~kb}$. The arteriviruses are described in more detail in the chapters by Snijder $e t$ al. and de Vries et al. in this volume.

The CSG would have liked to have assigned arterivirus to a taxon such that it drew attention to the similarities with the corona- and toroviruses while at the same time emphasizing the important differences. No proposal met with general approval. Consequently it was agreed that no formal proposal regarding the taxonomy of the arteriviruses would be made by the CSG and that the matter would be referred back to the ICTV Executive Committee. 
Table 1. Comparison of some features of coronaviruses, toroviruses and arteriviruses.

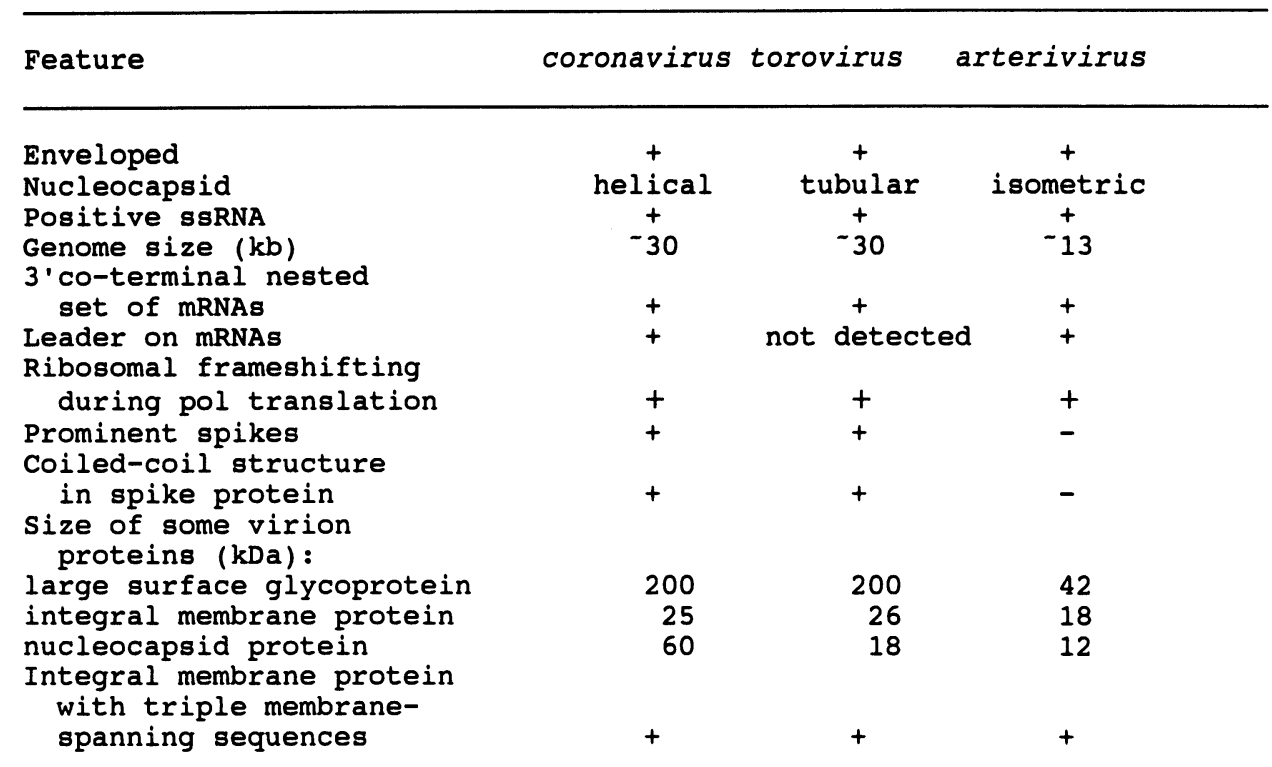

\section{REFERENCES}

1. D. Cavanagh, D.A. Brian, L. Enjuanes, K.V. Holmes, M.M.C. Lai, H. Laude, S.G. Siddell,W.J.M. Spaan, F. Taguchi and P.J. Talbot. Virology 176:306 (1990).

2. D.X. Liu and S.C. Inglis. Virology 185:911 (1991).

3. M. Godet, R. L'Haridon, J-F. Vautherot and H. Laude. Virology 188:666 (1992). 